\title{
Levantamento Florístico de Mata Ciliar em Áreas de Extração de Argila no MunicíPIo de São Roque do Canã̃-ES ${ }^{1}$
}

\section{Gerson Freitas Junior** \\ Zildo Gallo** \\ Flávia Cristina Sossae*** \\ Marcus C. Avezum Alves de Castro ****}

\section{RESUMO}

O município de São Roque do Canaã (ES) destaca-se pela produção de artefatos cerâmicos, porém essa atividade tem causado impactos negativos à mata ciliar do rio Santa Maria do Rio Doce. Assim, o presente trabalho objetivou estudar a composição florística da mata ciliar em áreas de extração de argila no município de São Roque do Canaã (ES), para auxiliar trabalhos de recomposição a partir de espécies nativas. Aárea estudada está muito alterada pela mineração, fato demonstrado pela escassez do número de espécies encontradas no levantamento florístico. Apesar de se observar a presença de várias espécies pioneiras e secundárias iniciais, também se observou que a exploração mineral gerou perda da camada superficial do solo, rica em matéria orgânica, ocasionando uma redução da capacidade produtiva do ecossistema.

Palavras-chave: Levantamento florístico; Mata ciliar; Argila; Mineração.

\footnotetext{
${ }^{1}$ Este texto deriva da dissertação (mestrado): "Revegetação de mata ciliar em áreas de extração de argila no município de São Roque do Canaã-ES" (FREITAS, 2009).

* Mestre pelo Programa de Mestrado em Desenvolvimento Regional e Meio Ambiente do Centro Universitário de Araraquara - Uniara.

**Doutor em Geociências; docente, orientador e pesquisador do Programa de Mestrado em Desenvolvimento Regional e Meio Ambiente do Centro Universitário de Araraquara - Uniara.

***Doutora em Ciências Biológicas; docente do curso de Ciências Biológicas e pesquisadora do Programa de Mestrado em Desenvolvimento Regional e Meio Ambiente do Centro Universitário de Araraquara Uniara.

**** Doutor em Hidráulica e Saneamento (EESC-USP); docente e pesquisador do Programa de Mestrado em Desenvolvimento Regional e Meio Ambiente do Centro Universitário de Araraquara - Uniara; docente do Departamento de Geologia Aplicada - IGCE - UNESP/Rio Claro.
} 


\section{INTRODUÇão}

A mata ciliar é definida como formações vegetais do tipo florestal que acompanha o curso dos rios. No Cerrado, em geral, essas matas são estreitas e com largura proporcional ao leito do rio, dificilmente ultrapassando 100 metros (RIBEIRO e WALTER, 1998) e constituem Áreas de Preservação Permanente (APP), segundo o Código Florestal, onde a vegetação original deve ser preservada para cumprir as suas diversas funções ambientais.

Segundo Felfilli et al. (2001), as matas ciliares e de galeria no Cerrado englobam cerca de $33 \%$ do número total de espécies de fanerógamas conhecidas para o bioma, e sua importância reside na função protetora que exerce sobre os recursos bióticos e abióticos (DURIGAN e SILVEIRA, 1999).

Em relação aos recursos bióticos, eles servem de refúgio para a fauna fornecendo abrigo e alimentação e atuando como corredor biológico, estimulando o fluxo gênico entre as populações. Quanto aos recursos abióticos, as matas ciliares têm importância fundamental na manutenção da qualidade da água. Elas absorvem a água proveniente do escoamento superficial das áreas adjacentes, contribuindo para a redução dos processos erosivos e do consequente assoreamento do leito do curso d'água. No processo de absorção, filtram a água que pode estar contaminada com resíduos químicos das atividades agrícolas, evitando a contaminação dos rios.

Além dos aspectos acima, a sombra proporcionada pela vegetação ciliar é importante para a estabilidade térmica da água, evitando alterações bruscas de temperatura que podem afetar a reprodução e sobrevivência de várias espécies de peixes (NAIMAN e DÉCAMPS, 1997; BARRELA et al., 2000; FONSECA et al., 2001).

Apesar de sua reconhecida importância, as matas ciliares no Estado do Espírito Santo encontram-se extremamente degradadas devido às ações indiscriminadas do homem, como o desmatamento, o mau uso do solo, as queimadas, a mineração e outras. Uma das medidas imprescindíveis para a conservação e recuperação dos recursos hídricos do Estado consiste na recuperação das áreas anteriormente ocupadas com matas ciliares, por meio da adoção de técnicas de silvicultura e do uso de espécies florestais adequadas a essa finalidade. Dentre as dificuldades encontradas por técnicos, produtores rurais e profissionais que atuam na recuperação de matas ciliares está a falta de material de orientação sobre procedimentos básicos necessários para a recuperação desse ecossistema (GARCIA e MORAES, 2001).

O município de São Roque do Canaã (ES), por exemplo, destaca-se pela produção de artefatos cerâmicos, porém essa atividade tem causado impactos 
negativos à mata ciliar do rio Santa Maria do Rio Doce. Assim, considerando a importância e a degradação das áreas que margeiam os rios, o presente trabalho objetivou estudar a composição florística da mata ciliar em áreas de extração de argila nesse município.

\section{Material e MÉtodos}

\section{1. Área de estudo}

$\mathrm{O}$ trabalho foi realizado na mata ciliar encontrada às margens do rio Santa Maria do Rio Doce, no município de São Roque do Canaã, que se localiza na microrregião Serrana Colonial Espírito-Santense, ocupando uma área de 341,74 Km (VENZEL, 2006). Possui população de aproximadamente 10.400 habitantes (IBGE, 2000) e faz divisa, ao norte, com Colatina; ao sul, com Santa Teresa; a leste, com João Neiva; e a oeste, com Itaguaçu (PROATER, 2008).

$\mathrm{O}$ clima da região é tropical, com temperatura média em torno de $23^{\circ} \mathrm{C}$. Predominam na região os solos latossolos vermelho-amarelos distróficos (PERRONE e MOREIRA, 2005).

\subsection{Metodologia}

Para a realização do levantamento florístico, a área foi percorrida periodicamente durante seis meses (junho a novembro de 2007). A metodologia utilizada para a investigação da cobertura vegetal existente nas margens do rio Santa Maria do Rio Doce foi uma adaptação do "levantamento rápido - (LR)" para amostragem da vegetação arbórea preconizada por Walter e Guarino (2006).

OLR visa coletar dados qualitativos de forma expedita, cujos princípios são similares ao método do "caminhamento" descrito por Filgueiras et al. (1994) e Ratter et al. (2000, 2001, 2003), que está baseado em levantamentos designados "wide patrolling" ("varredura"). Basicamente, o LR consiste da realização de ao menos três caminhadas em linha reta na vegetação, verificando as espécies visualizadas.

Para coleta de material vegetativo e reprodutivo utilizou-se tesoura de poda manual, além da coleta de fruto no chão, desde que se tivesse a certeza de que pertencia à árvore em estudo.

A identificação das plantas conhecidas que se encontram com materiais férteis foi feita por meio de um cadastro durante as visitas na área, onde apenas foram coletados fragmentos das espécies desconhecidas, ou de identificação duvidosa, para compará-los com a bibliografia (LORENZI, 2000; LORENZI, 2008; SOUZA e LORENZI, 2005) ou serem remetidos para especialistas.

\section{Resultados e Discussão}


As margens do rio Santa Maria do Rio Doce têm mata ciliar do tipo Floresta Estacional Semidecidual, que se caracteriza por uma dupla estacionalidade climática tropical, com intensas chuvas de verão seguidas de estiagem acentuada (superior a 60 dias), e também marcada pela queda das folhas, no percentual de 20 a 50\% dos componentes arbóreos dessa comunidade, em função dos períodos de deficiência hídrica (RODRIGUES e LEITÃO-FILHO, 2000).

Segundo a classificação adotada pelo IBGE (1992), esse tipo de vegetação se subdivide em quatro categorias, de acordo com a altitude de ocorrência: Floresta Aluvial - presentes nos terraços mais antigos das calhas dos rios; Floresta das Terras Baixas - entre as altitudes de 5 a 50 m; Floresta Submontana - 50 a 500 $\mathrm{m}$; Floresta Montana - 500 a $1.500 \mathrm{~m}$.

No rio Santa Maria do Rio Doce ocorre a Floresta Aluvial, sendo também denominada pelos termos "ribeirinha com influência fluvial sazonal", em conformidade com a classificação de formações ciliares proposta por Rodrigues e Leitão-Filho (2000).

A Floresta Estacional Semidecidual Ribeirinha com Influência Fluvial Sazonal corresponde, na região em estudo, às formações ocorrentes ao longo dos cursos d'água e diretamente influenciadas pela água, de forma sazonal. Constitui uma formação em geral estreita, porém conspícua ao longo do córrego. Nesses trechos, nas áreas que exibem cotas baixas e superfície de aplainamento praticamente sem declive, grande parte da superfície coberta pela vegetação marginal fica exposta às influências dos alagamentos periódicos.

A dinâmica da água do solo atua reconhecidamente na definição das características edáficas e vegetacionais da faixa ciliar. O mosaico vegetacional observado nessas formações reflete uma heterogeneidade ambiental resultante das distintas condições ecológicas existentes nas áreas, definidas por variações edáficas, topográficas, de encharcamento do solo, das formações vegetais do entorno, das características hidrológicas da bacia e do curso d'água, entre outros fatores (EITEN, 1963; 1992; COUTO et al., 1985; SCHIAVINI E ARAÚJO, 1989; RATTER et al., 1997; PIVELLO et al., 1998; RIBEIRO E WALTER, 1998; ARAÚJO et al., 1999).

Na mata ciliar presente nas margens do rio Santa Maria do Rio Doce foram encontradas 14 espécies, pertencentes a 8 famílias. As famílias com maior número de espécies são Fabaceae (6 espécies) e Poaceae (2), representando 57\% do total coletado. As famílias Apocynaceae, Euphorbiaceae, Moraceae, Nyctacinaceae, Phytolacaceae e Rubiaceae apresentaram apenas uma espécie (Tabela 1).

Segundo Haigh (1980) a forte perturbação ambiental contribui para o 
decréscimo da riqueza florística e a família Poaceae geralmente é a que possui maior número de espécies em ambientes antropizados, como demonstram os resultados semelhantes encontrados por Cervi et alli, (1988), Gavilanes e D'Angieri Filho (1991); Mautone et alli (1990) e Pedrotti e Guarim Neto (1998).

Das 14 espécies coletadas na mata ciliar, 1 é herbácea, 1 arbustiva e 12 são árvores. Portanto, se verifica a predominância de árvores. A maioria das espécies é nativa, sendo encontradas as plantas secundárias inicias (SI) em grande quantidade, duas pioneiras e apenas uma secundária tardia (Tabela 1).

As espécies exóticas, como Ricinus communis L., Bambusa vulgaris L. e Panicum maximum Jacq., estão presentes na área de estudo, possivelmente introduzidas por dispersores naturais ou, acidentalmente, pela ação antrópica.

A espécie Ricinus communis, que é possivelmente originária da África, hoje existe em todas as regiões de clima tropical e até temperado, em locais habitados e em áreas degradadas. Essas são especializadas para viverem em ambientes difíceis, seguindo as alterações causadas pelo homem. Com a urbanização e a agricultura sofrendo grande incremento devido ao crescimento populacional, elas tornam-se cada vez mais importantes para "cicatrizar" os espaços devastados (LORENZI, 2008). 
Tabela 1. Espécies encontradas na mata ciliar do rio Santa Maria do Rio Doce, São Roque do Canaã - SP, informações sobre o hábito $(H)$ (herb = herbácea, arb $=$ arbustiva, árv = árvore $)$ e Classe Sucessional $(\mathrm{CL})(\mathrm{P}=$ pioneira; $\mathrm{SI}=$ secundária inicial; $\mathrm{ST}=$ secundária Tardia; $\mathrm{ex}=$ exótica).

\begin{tabular}{|c|c|c|c|}
\hline Família/Espécie & Nomes populares & CL & $\mathbf{H}$ \\
\hline \multicolumn{4}{|l|}{ APOCYNACEAE } \\
\hline Peschiera fuchsiaefolia (A. DC.) Miers & $\begin{array}{l}\text { Leiteiro, jasmim-do-campo, } \\
\text { gancheira }\end{array}$ & $\mathrm{P}$ & $\operatorname{arv}$ \\
\hline \multicolumn{4}{|l|}{ EUPHORBIACEAE } \\
\hline Ricinus communis L. & Mamona, carrapateira & ex & arb \\
\hline \multicolumn{4}{|l|}{ FABACEACE/CAESALPINOIDEAE } \\
\hline Pterogyne nitens Tul. & Carne de vaca & SI & $\operatorname{arv}$ \\
\hline \multicolumn{4}{|l|}{ FABACEAE/CERCIDEAE } \\
\hline Bauhinia monandra Kurz. & Pata-de-vaca & SI & $\operatorname{arv}$ \\
\hline \multicolumn{4}{|l|}{ FABACEAE /MIMOSOIDEAE } \\
\hline Anadenanthera macrocarpa (Benth.) Brenan & Angico & SI & $\operatorname{arv}$ \\
\hline Inga sessilis (Vell.) Mart. & Ingá-do-brejo & SI & $\operatorname{arv}$ \\
\hline Plathymenia foliolosa Benth & Vinhático & SI & $\operatorname{arv}$ \\
\hline Pseudopiptadenia contorta (DC.) Lewis \& Lima & Angico vermelho & SI & $\operatorname{arv}$ \\
\hline \multicolumn{4}{|l|}{ MORACEAE } \\
\hline Ficus obtusiuscula Miquel & Figueira gameleira & ST & $\operatorname{arv}$ \\
\hline \multicolumn{4}{|l|}{ NYCTAGINACEAE } \\
\hline Bougainvillea spectabilis Willd. & Capa Garrote, primavera & ex & arb \\
\hline \multicolumn{4}{|l|}{ PHYTOLACCACEAE } \\
\hline Gallesia integrifolia (Spreng.) Harms & $\begin{array}{l}\text { Pau-de-mau-cheiro, pau-de- } \\
\text { alho }\end{array}$ & SI & $\operatorname{arv}$ \\
\hline \multicolumn{4}{|l|}{ POACEAE } \\
\hline Bambusa vulgaris L. & Bambu & ex & arb \\
\hline Panicum maximum Jacq. & $\begin{array}{l}\text { Capim colonhão, capim- } \\
\text { colonião }\end{array}$ & ex & herb \\
\hline \multicolumn{4}{|l|}{ RUBIACEAE } \\
\hline Genipa americana $\mathrm{L}$. & Genipapo & ST & arb \\
\hline
\end{tabular}

Fonte: Elaboração dos autores.

Na pesquisa desenvolvida por Venzel (2006) na nascente e margens do rio Santa Maria do Rio Doce, no município de Santa Tereza (ES), a autora realizou um diagnóstico da vegetação ciliar e identificou 18 espécies nativas pertencentes a 12 famílias, sendo que as espécies Anadenanthera macrocarpa (Benth.) Brenan (angico), Genipa americana L. (genipapo) e Peschiera fuchsiaefolia (A. DC.) Miers (leiteiro) também foram encontradas no presente estudo.

De acordo com Carvalho (1994), a espécie Anadenanthera macrocarpa possui grande abrangência geográfica, ocorrendo desde o sul da Bolívia até o 
norte da Argentina; no Brasil, só não aparece nos Estados da Região Sul, sendo uma planta comprovadamente calcícola, de crescimento rápido e tolerante a solos arenosos e rasos, e muito usados para recomposição de matas ciliares.

A Genipa americana L., conhecida popularmente como jenipapo ou jenipá, é uma Rubiaceae de porte arbóreo, com características de planta heliófita, semidecídua, seletiva higrófita, de ocorrência em áreas com florestas abertas e de vegetação secundária de várzeas situadas em locais temporário ou permanentemente inundados. Com ampla distribuição pelas regiões tropicais úmidas e subtropicais da América Latina, desde o México até a Argentina, a espécie parece desenvolverse melhor em áreas com pluviosidade entre 1.200 e 4.000 mm e com temperaturas médias anuais entre $18^{\circ} \mathrm{C}$ e $28^{\circ} \mathrm{C}$. No Brasil, sua ocorrência vai do Amapá aos Estados do Sul (LORENZI, 2008).

O leiteiro (Peschiera fuchsiaefolia) é uma planta daninha importante para as áreas de pastagem do país, cuja ocorrência se vem tornando crítica nas Regiões Centro-Oeste e Sudeste (LORENZI, 2000). A dispersão do leiteiro ocorre principalmente por meio de sementes, contidas em frutos carnosos que se rompem quando maduros, expondo sua polpa avermelhada (KISSMANN, 1997).

A área estudada está extremamente alterada pela ação antrópica, como a extração de argila, fato demonstrado pela escassez no número de espécies encontrado no levantamento florístico. Apesar de se observar a presença de várias espécies pioneiras e secundárias iniciais, que propiciam um ambiente adequado para a ocupação das espécies clímax, a exploração mineral gera perda da camada superficial do solo, rica em matéria orgânica, além dos horizontes mais profundos, proporcionando alterações nas propriedades edáficas, ocasionando uma redução da capacidade produtiva do ecossistema (FRANCO, 2008).

Na maioria das vezes, o solo das áreas degradadas apresenta níveis baixos de nutrientes e com características físicas e químicas diferentes, quando comparado aos solos originais. Nesse sentido, o êxito na recuperação de espaços degradados depende do manejo adequado para o uso do solo, bem como da elaboração de planejamento para a recuperação da paisagem, de lições da experimentação, da sensibilidade pública em relação ao meio ambiente, de uma condição política e social propícia e da conscientização das necessidades locais (KOPEZINSKI, 2000).

As propriedades físicas do solo que influenciam o crescimento e distribuição das espécies arbóreas, associadas à fertilidade do solo, exigem uma evolução cuidadosa do seu estado nutricional, com o intuito de programar uma aplicação correta de fertilizantes necessários para as plantas. No processo de recuperação, a determinação dos requerimentos físicos, nutricionais e biológicos do solo e um contexto multidisciplinar do manejo da área a ser recuperada constituem etapas 
importantes para se obter o sucesso esperado.

Portanto, na recuperação de áreas degradadas pela mineração, a revegetação é considerada parte essencial, não só pelo plantio de espécies vegetais, mas também pela seleção adequada dessas, visando reconstituir e acelerar o máximo possível o processo natural (LOURENZO, 1991).

\section{REFERÊNCIAS}

ARAUJO, A.R.B; TEIXEIRA, M.I.J.G.; RODRIGUES, R.R. Florística e fitossociologia de um trecho de cerrado no município de Franca-SP. Naturalia, São Paulo, v.24, p.153-170, 1999.

BARRELA, W. et al. As relações entre as matas ciliares, os rios e os peixes. In: RODRIGUES, R. R.; LEITÃO FILHO, H. F. (Ed.). Matas Ciliares: conservação e recuperação. São Paulo: EDUSP, 2000. p. 187-207.

CARVALHO, P.E.R. Espécies florestais brasileiras: recomendações silviculturais, potencialidades e uso da madeira. Colombo: EMBRAPA CNPF; Brasília: EMBRAPA - SPI, 1994. 640p.

CERVI, A C.; GUIMARÃES, O A; ACRA, L. A.; NEGRELLI, R. R. B.; SBALCHIERO, D. Catálogo das plantas ruderais da cidade de Curitiba, Brasil. Estudos preliminares III. Acta Biol. Par., v.17 n.1-4, p. 109 - 139, 1988.

COUTO, W. ; LEITE, G. C. ; KORNELIUS, E. The residual affect of P and lime on the performance of four tropical grasses in a high $\mathrm{P}$ fixing Oxisol. Agronomy Journal, Madison, v. 77, 1985.

DURIGAN, G.; SILVEIRA, E. R. da, Recomposição de mata ciliar em domínio de cerrado, Assis, SP. Scientia Florestales, Piracicaba, n. 56, p. 135-144, 1999.

EITEN, G. Vegetação do Cerrado. In: PINTO, M. N. (Org.). Cerrado: Caracterização, Ocupação e Perspectivas. Brasília: Editora Universidade de Brasília, 1994.

FONSECA, C. E. L. ;RIBEIRO, J. F.; REZENDE, R. P.; BALBINO, V. K. Recuperação da vegetação de matas de galeria: estudo de caso no Distrito Federal e entorno. In: RIBEIRO, J. F.; FONSECA, C. E. L.; SILVA, J. C. DE 
S. (Org.) Cerrado: Caracterização e recuperação de matas de galeria. Brasília: EMBRAPA Cerrados, 2001. p. 815-870.

FRANCO, A. A. Recomposição e Restauração em Áreas de Mineração. Workshop Recuperação e Manejo de Áreas Degradadas. Anais..., Jaguariúna, [online]. Disponível na Internet em: <http://www.abep.nepo.unicamp.br>, Acesso em: 24 abr. de 2008.

FELFILI, J. M. et al. Fitossociologia da vegetação arbórea. In: FELFILI, J. M.; SILVA JÚNIOR, M. C. Biogeografia do Bioma Cerrado: Estudo fitofisionômico na Chapada do Espigão Mestre do São Francisco. Brasília: Universidade de Brasília - Departamento de Engenharia Florestal, 2001.

FILGUEIRAS, T.S.; NOGUEIRA, P.E.; BROCHADO, A.L. \& GUALA II, G.F. Caminhamento: um método expedito para levantamentos florísticos qualitativos. Cadernos de Geociências. v.12, p. 39-43. 1994.

GARCIA; A.; MORES, M. Manual de operações técnicas de revegetação de matas ciliares. 2. ed. Vitória. Associação dos Engenheiros Florestais do Espírito Santo (AEFES), 2001.

GAVILANES,M.L. \& D'ANGIERI FILHO,C.N. Flórula ruderal da cidade de Lavras, MG. Acta Botanica Brasilica v.5, n.2, p. 77-88, 1991.

HAIGH, M. J. Ruderal communities in English cities. Urban Ecology, v.4, 329338, 1980.

IBGE - Instituto Brasileiro de Geografia e Estatística. Manual técnico da vegetação brasileira. IBGE, Rio de Janeiro, 1992.

KISSMANN, K. G. Plantas infestantes e nocivas. 2.ed. São Paulo: BASF, 1997. t. 2. 824 p.

KOPEZINSKI, I. Mineração X meio ambiente: considerações legais, principais impactos ambientais e seus processos modificadores. Porto Alegre: Editora da Universidade, 2000.

LORENZI, H. Árvores brasileiras: manual de identificação e cultivo de 
plantas arbóreas nativas do Brasil. Nova Odessa: Plantarum, 2008. v.2.

LORENZI, H. Árvores brasileiras: manual de identificação e cultivo de plantas arbóreas nativas do Brasil. Nova Odessa: Plantarum, 2000. v.2.

LORENZI, H. Manual de identificação e controle de plantas daninhas.

Nova Odessa: Plantarum, 2006.

LORENZI, H.; SOUZA, H.M. de; TORRES, M. A. V.; BACHER, L.B. Árvores exóticas no Brasil: madeiras, ornamentais e aromáticas. Nova Odessa: Plantarum, 367 p. 2003.

\section{LOURENZO, J.S. Regeneração Natural de uma Área Minerada de} Bauxita em Poços de Caldas, Minas Gerais. Dissertação de (Mestrado em Ciência Florestal) - Universidade Federal de Viçosa, Viçosa-MG. 1991.

MAUTONE, L.; BRANDÃO, M.; GUIMARÃES, E. F.; MIGUEL, J. R. Daninhas ocorrentes na zona serrana do Estado do Rio de Janeiro - Município de Petrópolis - 1. Acta bot. Bras., 1990. v 4, n.2 , p. 123-135, 1990.

NAIMAN, R.J. \& DÉCAMPS, H.. The ecology of interfaces:riparian zones. Annual Review of Ecology and Systematics, v. 28, p.621 -658, 1997.

PEDROTTI, D. E.; GUARIM NETO, G. Flora ruderal da cidade de Cuiabá, Mato Grosso, Brasil. Acta bot. bras. v.12, n.2, p. 135-143. 1998.

PERRONE; A.; MOREIRA, T.H.L. História e Geografia do Espírito Santo. 6. ed. Vitória: UFES, 2005.

PIVELLO, V.R.; BITENCOURT, M.D.; MANTOVANI, W.; MESQUITA JR., H.N. DE; BATALHA, M.A. \& SHIDA, C. Proposta de zoneamento ecológico para a reserva de cerrado Pé-de-Gigante (Santa Rita do Passa Quatro, SP). Brazilian Journal of Ecology v.2 p. 108-118, 1998.

PROATER. Programa de Assistência Técnica e Extensão Rural. Prefeitura da cidade de São Roque do Canaã, ES, 2008.

RATTER, J.A.; RIBEIRO, J.F. \& BRIDGEWATER, S. The Brazilian cerrado 
vegetation and threats to its biodiversity. Annals of Botany v.80, p. 223230, 1997.

RATTER, J.A.; BRIDGEWATER, S.; RIBEIRO, J.F.; DIAS, T.A.B. \& SILVA, M.R.. Estudo preliminar da distribuição das espécies lenhosas da fitofisionomia cerrado sentido restrito nos estados compreendidos pelo bioma Cerrado. Boletim do Herbário Ezechias Paulo Heringer v.5, p. 5-43. 2000.

RATTER, J.A.; BRIDGEWATER, S. \& RIBEIRO, J.F. Espécies lenhosas da fitofisionomia cerrado sentido amplo em 170 localidades do bioma Cerrado. Boletim do Herbário Ezechias Paulo Heringer 7: 5-112. 2001.

RATTER, J.A.; BRIDGEWATER, S. \& RIBEIRO, J.F. Analysis of floristic composition of the Brazilian cerrado vegetation III: comparison of the woody vegetation of 376 areas. Edinburgh Journal of Botany v.60, n.1 57-109. 2003.

RIBEIRO, J.F.; WALTER, B.M.T. Fitofisionomia do bioma Cerrado. In: SANO, S. M.; ALMEIDA, S.P. (Coords.). Cerrado: ambiente e flora. Planaltina: EMBRAPA, 1998 p.47-86.

RODRIGUES, R.R. Uma discussão nomenclatural das formações ciliares. In: RODRIGUES, R.R.; LEITÃO FILHO, H.de F. (Org.). Matas ciliares: conservação e recuperação. São Paulo: EDUSP- FAPESP, p. 91-99, 2001.

SCHIAVINI, I. \& ARAÚJO, G.M. Considerações sobre a vegetação da Reserva Ecológica do Panga (Uberlândia). Sociedade \& Natureza v.1, p. 6165,1989 .

VENZEL, S. M. Diagnóstico do Inventário da Nascente e Margens do Rio Santa Maria do Rio Doce, Município de Santa Teresa/ES.

Dissertação de (Mestrado em Gestão Auditoria Ambiental) - Universidade Politécnica da Cataluña-PUC, 2006.

WALTER, B.M.T. \& GUARINO, E.S.G. Comparação do método de parcelas com o "levantamento rápido" para amostragem da vegetação arbórea do Cerrado sentido estrito. Acta Botânica Brasilica v.20, p. 285-297, 2006. 


\section{Title: Floristic SurVey of Riparian Forest in AREaS of Clay Extraction in the City of SÃo Roque do CANã̃-ES}

\section{ABSTRACT}

The city of São Roque do Canaã (ES) stands out in the production of ceramic objects, but this activity has caused negative environmental impacts in the riparian forest of Santa Maria do Rio Doce river. So, this research had as aim to study the floristic composition of the riparian forest in areas of clay extraction in the city of São Roque do Canaã (ES) to help in the revegetation with native species. The studied area has changed a lot because of mining activities, which can be demonstrated by the shortage of the number of species found in the floristic survey. In spite of observing the presence of several species, pioneer and e initial secondary species, it was observed that the mineral exploration has caused the loss of the superficial layer of the soil, rich in organic material, leading to a reduction of the ecosystem productive capacity.

KEYWORDS: Floristic survey; Riparian Forest; Clay; Mining. 